\title{
Child poverty and deprivation in the UK
}

\author{
N J Spencer
}

There has been more than a decade of debate about the increase in child poverty during which the former Secretary of State, John Moore, announced 'the end of the line for poverty' (speech text 11 May 1989). Recently the National and well documented account commissioned by Unicef for a comparative study of child poverty in the industrialised countries. ${ }^{1}$

The association of poverty with childhood mortality and ill health is well established in developing countries ${ }^{2}$ and it is broadly accepted that the major determinants of improved health in developed countries have been better living conditions, sanitation, and higher standards of living. ${ }^{3}$ Against an overall trend of continuing improvement in mortality, inequalities of health outcomes between social groups persist and, indeed, may be widening. ${ }^{4}$

\section{Poverty and inequality in the 1980s}

No official poverty line is accepted in the UK. The concept of 'relative poverty', as defined by Townsend, ${ }^{5}$ has been used by most researchers. The numbers of children living in relative poverty increased sharply between 1979 and 1987. From 1979 to 1985 there was a $110 \%$ increase in children living in families dependent on supplementary benefit and a $25 \cdot 7 \%$ increase in children in families with incomes below $50 \%$ of the average. ${ }^{1}$ In 1985, 3.5 million children were living in or 'on the margins of' poverty. ${ }^{1}$

Families with children have displaced pensioners as the largest single group in poverty. ${ }^{1}$ The 'trickle-down' effect, by which the poor were supposed to benefit from the general increase in prosperity, has conspicuously failed. In terms of final income the share of the lowest fifth fell from $7 \cdot 1 \%$ in 1979 to $6.3 \%$ in 1987 and the highest fifth rose from 38 to $42 \%$. $^{6}$ The disposable income of the lowest income decile has actually fallen in real terms over the decade: lone parents with one child have suffered a loss of $>25 \%$ and couples with three or more children a loss of $15 \% .^{7}$

\section{The causes of child poverty in the $1980 \mathrm{~s}$} Bradshaw identifies economic trends, demographic changes, and social policies as contributing to the increase in prevalence of child poverty in the 1980 s. $^{1}$

School of Postgraduate Medical Education, The University of Warwick Coventry CV4 7AL

Correspondence to: Professor Spencer.

ECONOMIC TRENDS

Unemployment, short and long term, increased Children's Bureau has published an authoritative

subsequent fall, assisted by a total of 27 changes in the counting method, left pockets of high unemployment in many areas and the rates have increased again since April 1990. Low pay, affecting particularly women and the young in unskilled jobs, has increased. The number of wage earners falling below the Council of Europe's 'decency threshold' increased from $7 \cdot 8$ to $9 \cdot 9$ million. ${ }^{1}$

\section{DEMOGRAPHIC CHANGES}

The proportion of lone parent families doubled to $14 \%$ of all families with children between 1961 and 1986. There are now more than one million families headed by a lone parent, $90 \%$ of whom are women, containing 1.6 million children. An estimated one third of children will experience living in a lone parent household during their childhood. ${ }^{8}$ The rising divorce rate, peaking at $12 \cdot 7 / 1000$ married people in 1985 and particularly affecting younger marriages, and the increase from $9.2 \%$ in 1976 to $27 \%$ in 1989 of children born outside marriage have both contributed to this trend. The incidence of poverty is much higher in lone parent families with an estimated $70 \%$ living in or on the margins of poverty.

\section{SOCIAL POLICY}

Social policy in the 1980s has been shaped by the commitment of the government to reductions in taxation and public spending. Paradoxically, public spending has risen in real terms and taxation changes have benefited only those on higher incomes. ${ }^{10}$ Changes in the social benefits system, in particular the freezing of universal child benefit and the replacement of extra single payments by the loan based social fund, shown to increase, rather than reduce, indebtedness, 1 have affected low income families with children disproportionately.

Children in low income families have been affected by the reduction in public expenditure on housing. This reduction, along with other aspects of housing policy, has resulted in a major increase in homelessness with nearly 100000 households involving children registered homeless in $1988 .^{12}$ Constraints on education expenditure have limited services, notably school meals and preschool provision, from which poor children would be expected to benefit. ${ }^{1}$

The 1989 Children Act, due to come into force in October 1991, has been welcomed as sharply and reached 3.7 million in 1985-6. The century but, even here, severe financial con- 
straints on local authorities could jeopardise its implementation unless additional funding is made available.

\section{Effects on children's health \\ MORTALITY}

The decline in mortality rates of children has continued in the 1980s. However, UK infant mortality rates have declined more slowly than those in other European countries ${ }^{1}$ and social inequalities in infant mortality show no sign of narrowing. ${ }^{13} \mathrm{New}$ evidence suggests that the apparent decline in the differential in postneonatal mortality between social classes noted in the 1970s disappears when data of children born outside marriage are included in the analysis. ${ }^{14}$ A recent study, cited by Bradshaw, ${ }^{1}$ shows that England and Wales had the highest postneonatal mortality rate of seven selected countries; only black people in the USA had a higher rate. 'Preventable' causes of infant death are three times as common in social class $\mathrm{V}$ compared with social class $I^{15}$

\section{LOW BIRTH WEIGHT AND GROWTH}

The low birthweight rate has not declined in line with mortality remaining at $7 \%$ for the last 20 years. The improved survival of low birthweight infants has been attributed to improvements in neonatal care. Low birth weight, still a major cause of mortality and morbidity, shows a strong social class gradient and the UK rate is high compared with other countries in western Europe.

The trend in growth towards taller children seems to have slowed in the 1980s (Department of Health, 1990, unpublished). There has been no reduction in the social class height differentials at age $20-24$ between 1940 and $1980 .^{16}$

\section{MORBIDITY}

The paucity of morbidity data limits comment on trends in social class differentials. The 1986 General Household Survey shows a twofold increase in long standing illness in boys $(0-4$ years) from families headed by unskilled manual workers compared with boys from professional families but no differrence in the rates for girls. ${ }^{17}$ Children experiencing multiple hospital admissions have contributed disproportionately to the increased rate of admission to paediatric beds, ${ }^{18}$ and these children are more likely to live in deprived areas. Children admitted with significant pathology are also more likely to live in areas of deprivation (N J Spencer, B Pittapilly, $S$ Gentle, unpublished observations).

\section{Conflicting explanations of child health inequalities}

The differing explanations of health inequalities, structural and behavioural, are well illustrated in the response of Ann Widdecombe, the junior social security minister, to the recently published National Children's Homes' Poverty and Nutrition Survey, 1991. ${ }^{19}$ Miss Widdecombe attributed the study findings that low income families eat unhealthy diets and often go hungry to buying the wrong food and failing to shop where food is cheapest. The reality is far more complex. Low income families spend $30 \%$ of their income on food compared with $15 \%$ spent by high income families though, in total, high income families spend $38 \%$ more on food. ${ }^{20}$ The price of 'healthy' foods has increased faster than 'unhealthy' foods, choice is restricted by access to food outlets and calorie for calorie the 'unhealthy' foods are cheaper. ${ }^{21}$ In addition, low income families actually spend a larger proportion of their food budget on 'healthy' foods than high income families. ${ }^{22}$

Behaviour and 'lifestyle' are inextricably bound up with social circumstances and are themselves part of the complex mechanism by which inequalities in health develop. For the poor, 'lifestyle' choices are rarely 'free'.

\section{Conclusions}

Over the last decade the number of children living in families dependent on low income has increased sharply and families with children have taken over from pensioners as the single largest group in poverty. Income inequalities have become wider; children in lone parent and large families have been most affected by this trend.

The full effects of these changes are not yet clear. Bradshaw points to some encouraging trends in educational attainment, teenage crime, and smoking in childhood. ${ }^{1}$ This review has concentrated on effects on health. Health inequalities persist and there is evidence for widening of social class differentials.

The ability of health services to counteract the adverse effects on children is limited. Government policy is the key to minimising the economic hardship of families with children and reversing the trend of the last decade. Essential to this is a reduction in unemployment and the elimination of low pay. Policies facilitating the combination of work and child care for mothers and enhancing the income of families with children would be positive steps.

Responsive, appropriate services for poor families are important but these families desperately need advocates. The United Nation's Convention on Children's Rights and the World Health Organisation's Health For All Targets, both of which emphasise reduction of health inequalities, can be used in advocacy. Good data are essential for effective advocacy. Currently collected data and that available from carefully designed research could form the basis of an annual report on the state of children in the $\mathrm{UK}$, as proposed by Bradshaw. In addition, this would ensure that statistical information available to government is brought into the public domain annually.

Paediatricians are dealing daily with the consequences of social policies that perpetuate health inequalities. It is time we 'looked upstream' and contributed actively to promoting child and family centred policies.

1 Bradshaw J. Child poverty and deprivation in the UK.' London: National Children's Bureau, 1990. 
2 Grant J. The state of the world's children, 1991. New York: Oxford University Press, 1991.

3 Rose G. Reflections on the changing times. BMF 1990;301: 683-7.

4 Wilkinson RG. Class mortality differentials, income distribution and trends in poverty 1921-1981. Fournal of Social Policy tion and trends in

5 Townsend P. Poverty in the UK. Harmondsworth: Penguin,

6 Central Statistical Office. Economic trends. London: HMSO, 1990. (No 439, May.)

7 Townsend P. The poor are poorer: a statistical report on changes in the living standards of rich and poor in the UK 1979-1989. Bristol: University of Bristol, Department of Social Policy and Social Planning, 1991 .

8 Clarke L. Children's changing circumstances: recent trends and future prospects. London: University of London, Centre for Population Studies, 1989.

9 Millar J. Poverty and the lone-parent family: the challenge to social policy. Aldershot: Avebury, 1989.

10 Hill J. Changing tax: how the tax system works and how to change it. London: Child Povery Action Group, 1989.

11 Smith R. Under the breadline: Claimants, the social fund and the voluntary sector-a case study. London: The Children's the voluntary sect

12 Lowry S. Housing and health. London: BMJ Publications, 1991.
13 National Children's Bureau. Investing in the future: child health ten years after the Court report. London: National Children's Bureau, 1987.

14 Pamuk ER. Social class inequality in infant mortality in England and Wales from 1921-1980. European fournal of Population Studies 1988;4:1-21.

15 Office of Population Censuses and Surveys. Occupational mortality 1979-80 and 1982-83. London: HMSO, 1988.
Offorice (Childhood supplement series D5 No 8.)

16 Carr-Hill R. Trends in health. York: Centre for Economics, University of York, 1986.

17 Office of Population Censuses and Surveys. General household survey 1986. London: HMSO, 1988.

18 Spencer NJ, Lewis MA. Multiple admissions under 2 years of age. Arch Dis Child 1991;66:938-40.

19 National Children's Homes. National Children's Homes' Poverty and Nutrition Survey, 1991. London: National Children's Homes, 1991.

20 Shepherd J. Food facts. London: London Food Commission, 1986.

21 Lobstein T. Poor children and cheap calories. London: British Paediatric Association 1988. Community Paediatric Group Newsletter, Autumn: 4.

22 Department of Employment. Family expenditure survey. London: HMSO, 1988.

Inheritance, irritants, infants, and asthma

Medicine is the study of the ways in which genetic constitution interacts with environment to produce disease. It makes sense therefore in a chronic disorder of early onset to try to observe subjects in as pristine a condition as possible in the hope of minimising the environmental contribution. Recent technical advances have made it possible to study airway reactivity in small infants and a group in Perth, Australia has looked at babies between 2 and 10 weeks of age (Sally Young and colleagues, Nerv England fournal of Medicine 1991;324:1168-73).

Sixty three normal healthy babies were studied before and after histamine challenge using an inflation jacket and measuring maximal airflow at functional residual capacity (Vmax FRC). They were divided into four groups defined according to parental smoking habits and family history of asthma in first or second degree relatives. Taking $\mathrm{F}+$ and $\mathrm{F}-$ to indicate the presence or absence of a family history of asthma, $S+$ to indicate that one or both parents smoked during the pregnancy and $S-$ to indicate that neither parent smoked, the groups were: (1) F-, $S-$ (2) F+, $S-$ (3) F-, S + and (4) F+ S+ .

Before histamine challenge there was no statistically significant difference in Vmax FRC between the four groups of babies though it is noticeable that mean Vmax FRC was lower in those with a family history of asthma (groups 2 and 4). Airway responsiveness as measured by the lowest concentration of histamine to provoke a $40 \%$ drop in $V_{\max }$ FRC was increased in groups 2, 3, and 4 compared with group 1 . Thus both parental smoking and family history of asthma led to the baby having more irritable airways. There was no significant difference between groups 2,3 , and 4 in this respect and in particular group 4, in which both factors operated, did no worse than the other 2 groups.

There was a great deal of overlap between the groups as regards the measured values but it is perhaps surprising that significant differences were found at all in view of the all inclusive definition of parental smoking and the inclusion of both first and second degree relatives in the family history. It would be interesting to repeat the work looking at babies with only a first degree family history and those who parents were heavy smokers. Nevertheless the work in Perth has shown that airway reactivity occurs in very young babies and that both genetic and environmental influences appear to play a part even at this young age. The authors intend to continue their studies throughout infancy in an attempt to define more clearly the influences on airway reactivity. 